\title{
The effect of menstrual cycle phase on exercise capacity measured by treadmill exercise test
}

\author{
Sadan YAZAR, Mehmet YAZICI \\ Department of Cardiology, Konya Education and Research Hospital, Konya, Turkey \\ Address Correspondence to S. Yazar, sadanyazar@yahoo.co.uk
}

\begin{abstract}
The aim of this study was to explore the impact of the menstrual phases on exercise capacity parameters measured by a treadmill exercise test in sedentary premenaupausal women. Exercise capacity expressed in terms of metabolic equivalents (MET) and exercise duration was measured by performing treadmill exercise tests in 30 women (mean age: $29 \pm 5.8$ years) with regular menstrual cycles at two points during their menstrual cycles: the late-follicular (LF) phase and the mid-luteal (ML) phase. The exercise duration was significantly higher $(\mathrm{P}<0.05)$, and the exercise capacity (in MET) tended to be higher $(\mathrm{P}=0.075)$ in the ML phase than in the LF phase. These results suggested that the menstrual phases in sedentary women can have an influence on exercise capacity. These changes may be attributed to the relative changes in the female steroid hormones between the LF and the ML phases.
\end{abstract}

Keywords: Estrogen, maximal oxygen uptake, menstrual cycle, metabolic equivalent, treadmill.

\section{INTRODUCTION}

Female steroid hormone profiles continuously change throughout ovulatory menstrual cycles. While estrogen levels begin to increase halfway through the follicular phase to reach a peak just prior to ovulation, both estrogen and progesterone are elevated during the middle of the luteal phase (36). Different hormonal environments in the follicular and luteal phases may have implications on exercise capacity. Several studies have reported differences in performance such as the time to exhaustion $(14,26,28,29,34,35,37)$, while others have reported that exercise performance did not differ during the phases of the menstrual cycle $(5,9,10,11,13,31,38,39)$. Therefore, there is no consensus regarding the effect of the menstrual cycle on exercise capacity.

The duration of exercise is an objective measurement of exercise capacity (functional capacity) (1,17). Another measurement of exercise capacity is the estimation of maximal oxygen uptake during exercise, which can be converted to metabolic equivalents (MET; 1 MET $=3.5 \mathrm{~mL}$ $\left.\mathrm{O}_{2} / \mathrm{kg} / \mathrm{min}\right) \quad(6,24,33)$. MET is a widely-used physiological concept that expresses the energy cost of physical activities as a multiple of the resting metabolic rate. Exercise capacity can be easily measured by performing a symptom-limited exercise test. Epidemiologic studies have noted that exercise capacity (measured in METs) and exercise duration are inversely and strongly related to cardiovascular events and the overall mortality risk in asymptomatic women and men $(5,15,20,32,40)$. To the best of our knowledge, there have been no reports about the influence of the menstrual cycle on exercise capacity (in METs). The aim of this study was to investigate the effects of the menstrual cycle on exercise capacity, as estimated by a treadmill exercise test, in premenopausal women.

\section{MATERIAL \& METHODS}

\section{Subject Selection}

Thirty non-obese healthy female subjects, 22-37 years old (average age: $29 \pm 5.8$ years), were included in the study. For the 12 months prior to the commencement of the study, their menstrual cycles were regular and ranged from 25 to 30 days (average; $27 \pm 1.6$ days). We determined the length of the menstrual cycle by counting the number of days from the first day of one bleeding episode up to and including the day before the start of the next bleeding episode. A menstrual cycle was considered normal when menstruation regularly occurred between 25- and 31-day intervals (18). All participants were sedentary and non-smokers. Each 
participant underwent a detailed physiological examination prior to the study. According to a health history questionnaire, none of them had any chronic diseases and none were pregnant or lactating. They also did not take any medications, including estrogen/progesterone contraceptives, hormone replacement therapy or other drugs.

The study was approved by the ethical committee of the Konya Education and Research Hospital. All subjects gave written informed consent prior to participation.

\section{Protocol}

All subjects underwent a symptom-limited treadmill test according to the standard Bruce protocol in each of the following phases of the menstrual cycle: the late-follicular (LF) phase $(11 \pm 2$ days after the first day of bleeding) and the midluteal (ML) phase $(21 \pm 2$ days after the first day of bleeding). Menstrual status was determined based on the cyclic history.

The peak exercise time was recorded in minutes. The peak workload was estimated as METs. One MET is a unit of basal oxygen consumption, which is equivalent to an oxygen consumption of $3.5 \mathrm{~mL} / \mathrm{kg}$ body weight per minute (24). The exercise capacity (in METs) was estimated on the basis of the speed and the grade of the treadmill(16). Subjects were encouraged to exercise until they experienced maximal exhaustion in the absence of symptoms or other indicators of ischemia.

\section{Statistical analysis}

All statistical analyses were performed by SPSS version 15.0 for Windows.(SPSS Inc., IL, USA). Results were given as mean \pm standard deviation. The paired sample $t$-test was used for the comparison of both phases of the menstrual cycle. $\mathrm{P}$ values of $<0.05$ were considered as statistically significant.

\section{RESULTS}

The treadmill exercise stress test parameters measured during the LF and ML phases of the menstrual cycle are listed in Table 1. The exercise duration (time of exhaustion) was significantly longer, and the peak exercise capacity (in METs) tended to be higher in the ML phase compared with those measurements in the LF phase. While the peak heart rate did not differ during the menstrual phases, the resting heart rate was higher in the follicular phase.
Table 1. Exercise capacity parameters estimated by treadmill exercise test during each menstrual phase (Values are mean $\pm \mathrm{SD}$, $\mathrm{n}=30)$.

\begin{tabular}{lccc}
\hline & $\begin{array}{c}\text { Follicular } \\
\text { phase }\end{array}$ & $\begin{array}{c}\text { Luteal } \\
\text { phase }\end{array}$ & P value \\
\hline & & & \\
Basal heart rate $(\mathrm{bpm})$ & $100 \pm 18$ & $94 \pm 13$ & 0.075 \\
Peak heart rate $(\mathrm{bpm})$ & $177 \pm 9$ & $174 \pm 11$ & $\mathrm{NS}$ \\
METs & $12.9 \pm 1.8$ & $13.3 \pm 1.8$ & 0.075 \\
Exercise duration $(\mathrm{min})$ & $10.7 \pm 1.7$ & $11.4 \pm 1.8$ & 0.001
\end{tabular}

$\mathrm{bpm}=$ per minute beat $; \mathrm{MET}=$ metabolic equivalent

\section{DISCUSSION}

Unlike previous studies of menstrual cycle phase and exercise performance, we examined the exercise capacity (in MET) using the final speed and grade of the treadmill, as defined by the Bruce protocol. Similar to the findings of other studies $(14,26,28,29,34,35,37)$, this study demonstrated that there were differences in exercise performances during the follicular and luteal phases. In two studies, the exercise capacity, expressed as peak oxygen uptake $\left(\mathrm{VO}_{2}\right.$ peak), was higher during the follicular phase in untrained (37) and trained (28) subjects. Other studies have found improved exercise performance and time to exhaustion during the luteal phase in both untrained $(26,29,35)$ and trained $(14,34)$ subjects. The women in the present study demonstrated a higher exercise capacity (in METs) and exercise duration during the ML phase than during the LF phase. This finding is contrary to the results of other reports which had noted no difference $\quad(5,9,10,11,13,31,38,39)$. Inconsistent findings regarding the interaction between the menstrual cycle and exercise performance may be due to the sample size, age, physical condition status of the subjects, the choice of phase (menstruation, follicular phase, ovulation, and luteal phase), and the different methods that may be used to identify normal menstrual function and to verify the specific menstrual phase.

During exercise, both estrogen and progesterone concentrations increase; however, the increase in estrogen, which is relative to progesterone during exercise, is greater in the luteal phase than in the follicular phase $(25,26)$. Studies which found a better exercise performance during the luteal phase had a higher estrogen to progesterone concentration ratio $(\mathrm{E} / \mathrm{P})$, whereas the studies reporting no changes in performance had a lower E/P ratio $(2,3)$. Furthermore, a number of studies found a lower rate of glycogen use $(8,12,17,22,23,30)$ and a higher whole body lipid use 
in the luteal phase than in the follicular phase $(7,21,41)$. For that reason, increased exercise performance in the luteal phase may be related with the magnitude of increase in estrogen during the luteal phase compared with the follicular phase, and can be attributed to the metabolic effects of estrogen.

In this study, menstrual status was determined according to cycle history and exercise capacity estimated during times of high (LF and ML phase) hormonal influence. However, the serum endogenous sex hormone concentrations were not measured during the menstrual phases. Thus, our findings cannot be attributed to specific hormones. This was a major limitation of the present study. However, pre-test hormone concentrations may not necessarily reflect the hormone concentrations during the test because the estrogen and progesterone levels increased during exercise.

In conclusion, different hormonal statuses and variations in hormonal response to exercise during the follicular and luteal phases contributed to the improved exercise capacity during the ML phase. Future studies that evaluate the combined influence of endogenous sex hormone concentrations, age, body mass index (BMI), and physical condition on exercise performance during the menstrual cycle may more clearly determine the relationship between exercise capacity and the menstrual cycle.

\section{REFERENCES}

1. Arena R, Myers J, Williams MA, Gulati M, Kligfield P, Balady GJ, Collins E, Fletcher G. American Heart Association Committee on Exercise, Rehabilitation, and Prevention of the Council on clinical cardiology; Assessment of functional capacity in clinical and research settings: a scientific statement from the American Heart Association Committee on Exercise, Rehabilitation, and Prevention of the Council on clinical cardiology and the Council on Cardiovascular Nursing. Circulation. 2007;116:329-343.

2. Bailey SP, Zacher CM, Mittleman KD. Effectof menstrual cycle phase on carbohydrate supplementation during prolonged exercise to fatique. J Apple Physiol. 2007;88:690697.

3. Beidleman BA, Rock PB, Muza SR, Fulco CS, Forte VA Jr, Cymerman A. Exercise $V_{E}$ and physical performance at altitude are not affected by menstrual cycle phase. J Apple Physiol. 1999;86:1519-26

4. Bemben DA, Salm PC, Salm AJ. Ventilatory and blood lactate responses to maximal treadmill exercise during the menstrual cycle. J Sports Med Phys Fitness.1995;35:257-262

5. Blair SN, Kohl HW III, Paffenbarger RS, Clark DG, Cooper KH, Gibbons LW. Physical fitness and all-cause mortality: a prospective study of healthy men and women. JAMA. 1989;262:2395-2401.

6. Bruce, RA, Kusumi, F, and Hosmer, D. Maximal oxygen intake and nomographic assessment of functional aerobic impairment in cardiovascular disease. Am Heart J. 1973;85:546-562.

7. Campbell SE, Angus DJ, Febbraio MA. Glucose kinetics and exercise performance during phases of the menstrual cycle: effect of glucose ingestion. Am J Physiol. 2001;281:E817-825.

8. Campbell SE, Febbraio MA. Effect of the ovarian hormones on GLUT4 expression and contraction-stimulated glucose uptake. Am J Physiol. 2002;282:E1139-1146.

9. Casazza GA, Suh S-H, Miller BF, Navazio FM, Brooks GA. Effects of oral contraceptives on peak exercise capacity. J Appl Physiol. 2002; 93:1698-1702.

10. Dean TM, Perreault L, Mazzeo RS, Horton TJ. No effect of menstrual cycle phase on lactate threshold. J Appl Physiol. 2003;95: 2537-2543.

11. De Souza MJ, Maguire MS, Rubin KR, Maresh CM. Effects of menstrual phase and amenorrhea on exercise performance in runners. Med. Sci. Sports Exerc. 1990; 22:575-580.

12. Devries MC, Mazen JH, Phillips SM, Tarnopolsky MA. Menstrual cycle phase and sex influence muscle glycogen utilization and glucose turnover during moderate-intensity endurance exercise. Am J Physiol. 2006;291:R1120-1128.

13. Dombovy ML, Bonekat HW, Williams TJ, et al. Exercise performance and ventilatory response in the menstrual cycle. Med Sci Sports Exerc 1987;19:111-111-117.

14. Doskin VA, Kozeeva TV, Listskay TS, Shokina EV. Changes in working capacity of female atlets in different phases of menstrual cycle. Hum Physiol. 1992;5:144-149.

15. Ekelund LG, Haskell WL, Johnson JL, Whaley FS, Criqui MH, Sheps DS. Physical fitness as a predictor of cardiovascular mortality in asymptomatic North American men: the Lipid Research Clinics Mortality Follow-up Study. N Engl J Med. 1988;319:1379-1384.

16. Foster C, Jackson AS, Pollock ML, Taylor MM, Hare J, Sennett SM, Rod JL, Sarwar M, Schmidt DH. Generalized equations for predicting functional capacity from treadmill performance. Am Heart J. 1984;107:1229-123.

17. Friedlander AL, Casazza GA, Horning MA, Huie MJ, Piacentini MF, Trimmer JK, Brooks GA. Training- induced alterations of carbohydrate metabolism in women: women respond differently from men. J Appl Physiol. 1998;85:11751186.

18. Gibbons RJ, Balady GJ, Bricker JT, et al. American College of Cardiology/American Heart Association Task Force on Practice Guidelines ( Committee to Update the 1997 Exercise Testing Guidelines). Circulation. 2002;106:1883-1892.

19. Golub S. Periods: From Menarche to Menopause. 1992;Sage puplications,Newbury Park. Jette M, Sidney K, Blumchen G. Metabolic equivalents (METS) in exercise testing, exercise prescription, and evaluation of functional capacity. Clin Cardiol. 1990;13:555-556.

20. Gulati M, Pandey DK, Arnsdorf MF, Lauderdale DS, Thisted RA, Wicklund RH, Al-Hani AJ, Black HR. Exercise capacity and the risk of death in women: the St James Women Take Heart Project. Circulation. 2003;108:1554-1559.

21. Hackney AC, Curley CS, Nicklas BJ. Physiological responses to submaximal exercise at the mid-follicular, ovulatory and mid-luteal phases of the menstrual cycle. Scand J Med Sci Sports. 1991;1:94-98. 
22. Hackney AC. Influence of oestrogen on muscle glycogen utilization during exercise. Acta Physiol Scand. 1999;167:273 274.

23. Hatta H, Atomi Y, Shinohara S, Yamamoto Y, Yamada S. The effects of ovarian hormones on glucose and fatty acid oxidation during exercise in female ovariectomized rats. Horm Metab Res. 1988;20:609-611.

24. Jette M, Sidney K, Blumchen G. Metabolic equivalents (METS) in exercise testing, exercise prescription, and evaluation of functional capacity. Clin Cardiol. 1990; 13:555556.

25. Jurkovski JE, Jones NL, Walker C, Younglai EV, Sutton JR. Ovarian hormonal responses to exercise. J Appl Physiol. 1978;44:109-114.

26. Jurkowski JE, Jones NL, Toews CJ, Sutton JR. Effects of menstrual cycle on blood lactate, O2 delivery, and performance during exercise. J Appl Physiol. 1981;51:14931499.

27. Keizer HA, Rogol AD. Physcial exercise and menstrual cycle alterations: what are the mechanism? Sports Med. 1990;10:218-235.

28. Lebrun CM, McKenzie DC, Prior JC, Taunton JE. Effects of menstrual cycle phase on athletic performance. Med Sci Sports Exerc. 1995;27:437-444.

29. Masterson G. The impact of menstrual phases on anaerobic power performance in collegiate women. J. Strength Cond. Res.1999;13:325-329

30. Matute ML, Kalkhoff RK. Sex steroid influence on hepatic gluconeogenesis and glycogen formation. Endocrinology. 1973;92:762-768.

31. Miskec CM, Potteiger JA, Nau KL, Zebras CJ. Do varing enviromental and menstrual cycle conditions affect anaerobic power output in female athletes. J Strength Cond Res. 1995; 11:219-223.
32. Mora S, Redberg RF, Cui Y, Flaws JA, Sharrett AR, Blumenthal RS. Ability of exercise testing to predict cardiovascular and all-cause death in asymptomatic women: a 20-year follow-up of the Lipid Research Clinics Prevalence Study. JAMA. 2003;290:1600-1607.

33. Morris CK, Myers J, Froelicher VF, Kawaguchi T, Ueshima $\mathrm{K}$, Hideg ANomogram based on metabolic equivalents and age for assessing aerobic exercise capacity in men. J Am Coll Cardiol. 1993;22:175-182.

34. Nicklas BJ, Hackney AC, Sharp RL. The menstrual cycle and exercise: performance, muscle glycogen, and substrate responses. Int J Sports Med. 1989;10:264-269.

35. Redman LM, Weatherby RP. Measuring performance during the menstrual cycle: a model using oral contraceptives. Med Sci Sports Exerc. 2004;36:130-136.

36. Reilly T. The menstrual cycle and human performance: an overview. Biol Rhythm Res. 2000;31:29-40.

37. Schoene RB, Robertson HT, Pierson DJ, Peterson AP. Respiratory drives and exercise in menstrual cycles of athletic and nonathletic women. J Appl Physiol. 1981;50:1300-1305.

38. Smekal G, Von Duvillard SP, Frigo P, Tegelhofer T, Pokan R, Hofmann P, Tschan H, Baron R, Wonisch M, Renezeder K, Bachl N. Menstrual cycle: no effect on exercise cardiorespiratory variables or blood lactate concentration. Med Sci Sports Exerc. 2007;39 (7):1098-1106.

39. Stephenson LA, Kola MA, Wilkerson JE. Perceived exertion and anaerobic threshold during the menstrual cycle. Med Sci Sports Exerc. 1982;14:218-222.

40. Wei M, Kampert JB, Barlow CE, Nichaman MZ, Gibbons LW, Paffenbarger RS Jr, Blair SN. Relationship between low cardiorespiratory fitness and mortality in normal-weight, overweight, and obese men. JAMA. 1999;282:1547-155.

41. Zderic TW, Coggan AR, Ruby BC. Glucose kinetics and substrate oxidation during exercise in the follicular and luteal phases. J Appl Physiol. 2001;90:447-453. 